\title{
Empowering Tenaga Kependidikan di MA Unggulan Mukhtar Syafa'at Blokagung Banyuwangi
}

\author{
Siti Aimah ${ }^{1}$, Umi Nur Syarifah ${ }^{2}$ \\ e-mail : sitiaimah@iaida.ac.id ${ }^{1}$, uminursyarifah98@gmail.com ${ }^{2}$ \\ Prodi Manajemen Pendidikan Islam \\ Institut Agama Islam Darussalam BlokagungBanyuwangi
}

\begin{abstract}
The applied objectives in this study are: (1) Knowing the recruitment of educational personnel at MA Unggulan Mukhtar Syafa'at Blokagung Tegalsari Banyuwangi Schooling Year 2019/2020; (2) Knowing a placement of educational staff at MA UnggulanMukhtar Syafa'at Blokagung Tegalsari Banyuwangi Schooling Year 2019/2020; (3) Knowing the empowerment of educational staff at MA UnggulanMukhtar Syafa'at Blokagung Tegalsari Banyuwangi Schooling Year 2019/2020; (4) Knowing the supporting and obstacles process of empowering educational staff at MA Unggulan Mukhtar Syafa'at Blokagung Tegalsari Banyuwangi Schooling Year 2019/2020. This research method uses the descriptive qualitative. The data collection through out the observation, interview and documentation. The analysis data uses 3 models of interactive analysis while the technical validity data uses triangulation. The result of the research : the recruitment process of the educational staff at MA unggulan Mukhtar Syafa'at Blokagung Tegalsari Banyuwangi has been running systematically. The placement of adecation personnel at MA unggulan Mukhtar Syafa'at Blokagung Tegalsari Banyuwangi is in accordance with the field of expertise and skills possessed and continued with the guidance which is carried out by the foundation's management. The process of educational staff empowering has been very good. Supporting and inhibiting factors in the process of empowering educational staff at MA unggulan Mukhtar Syafa'at Blokagung Tegalsari Banyuwangiis: (a) Supporting factors includes the systematic education personnel recruitment (b) Inhibiting factors : (1) there is a limitation of the employees that causes there are currently work educational staff who get unfinished task in accordance with their fields of expertise. (2) There are several types of work that have not been filled.
\end{abstract}

Keywords: Empowering, Educational Staff.

\section{Abstrak}

Tujuan yang ditetapkan dalam penelitian ini adalah: (1) Mengetahui rekrutmen tenagake pendidikan di MA Unggulan Mukhtar Syafa'at Blokagung Tegalsari Banywwangi Tahun Pembelajaran 2019/2020; (2) Mengetahui placement/penempatan tenaga kependidikan di MA Unggulan Mukhtar Syafa'at Blokagung Tegalsari Banyuwangi Tahun Pembelajaran 2019/2020; (3) Mengetahui pemberdayaan tenaga kependidikan di MA Unggulan Mukhtar Syafa'at Tahun Pembelajaran 2019/2020; (4) Mengetahui faktor pendukung dan penghambat proses pemberdayaan tenaga kependidikan di MA Unggulan Mukhtar Syafa'at Blokagung Tegalsari Banyuwangi Tahun Pembelajaran 
2019/2020. Metode penelitian ini menggunakan deskriptif kualitatif, pengumpulan datanya melalui wawancara, observasi dan dokumentasi. Analisis data menggunakan analisis interaktif tiga model, sedangkan teknik keabsahan data menggunakan triangulasi. Hasil penelitiannya: Proses rekrutmen tenaga kependidikan di MA unggulan Mukhtar Syafa'at Blokagung Tegalsari Banyuwangi sudah berjalan secara sistematis. Penempatan tenaga kependidikan di MA unggulan Mukhtar Syafa'at Blokagung Tegalsari Banyuwangi sudah sesuai dengan bidang keahlian dan skill yang dimiliki dan dilanjutkan dengan adanya pembinaan yang dilaksanakan oleh pihak yayasan. Proses pemberdayaan tenaga kependidikan di MA unggulan Mukhtar Syafa'at Blokagung Tegalsari Banyuwangi sudah sangat baik. Fakto rpendukung dan penghambat proses pemberdayaan tenaga kependidikan di MA unggulan Mukhtar Syafa'at Blokagung Tegalsari Banyuwangi meliputi: (a) Faktor pendukung meliputi rekrutmen tenaga kependidikan yang sistemasis; (b) Faktor penghambat meliputi: (1) Adanya keterbatasan pegawai yang menyebabkan masih terdapat tenaga kependidikan yang merangkap tugas dan mendapatkan tugas belum sesuai dengan bidang keahliannya; (2) Terdapat beberapa job pekerjaan yang belum terisi.

Kata Kunci: Empowering, Tenaga Kependidikan.

\section{A. Pendahuluan}

\section{Latar Belakang Masalah}

Sumber Daya Manusia (SDM) merupakan modal dasar pembangunan nasional, oleh karena itu maka kualitas SDM senantias aharus dikembangkan dan diarahkan agar bisa mencapai tujuan yang diharapkan. Berbicara mengenai SDM sebenarnya dapat dilihat dari 2 aspek yaitu aspek kualitas dan aspek kuantitas. Aspek kuantitas mencakup jumlah SDM yang tersedia, sedangkan aspek kualitas mencakup kemampuan SDM baik fisik maupun non fisik atau kecerdasan dan mental dalam melaksanakan pembangunan. Upaya dalam mewujudkan misi dan visi organisasi dapat memanfaatkan SDM yang dimilikinya seoptimal mungkin, supaya dapat memberikan added value bagi organisasi tersebut. Oleh karena itu untuk mewujudkannya, diperlukan SDM yang terampil dan handal di bidangnya.

Manajemen merupakan hal yang sangat penting dalam kehidupan, dengan manajemen kinerja sebuah organisasi dapat berjalan secara maksimal. Demikian juga dengan lembaga pendidikan dengan manajemen 
yang baik, maka sebuah institusi pendidikan akan dapat berkembang secara optimal sebagaimana diharapkan. Salah satu manajemen yang sangat penting diterapkan di institusi pendidikan yakni manajemen sumber daya manusia. Manajemen sumber daya manusia di sekolah harus dilaksanakan dengan baik dengan tujuan untuk memberdayakan tenagatenaga kependidikan secara efektif dan efisien untuk mencapai hasil yang optimal. Namun tetap dalam kondisi yang menyenangkan.

Keberhasilan program pendidikan melalui proses belajar-mengajar sangat dipengaruhi oleh banyak faktor salah satu diantaranya ialah tersedianya tenag akependidikan yang memadai, kompeten dan profesional. Tenaga kependidikan merupakan salah satu sumber daya yang penting dan utama dalam menunjang proses pembelajaran di sekolah, untuk itu perlu dilakukan peningkatan dalam pemberdayaan dan pengembangan keprofesian secara berkelanjutan agar tujuan sekolah dapa ttercapai secara maksimal.

Dalam Al-Qur'an Allah berfirman :

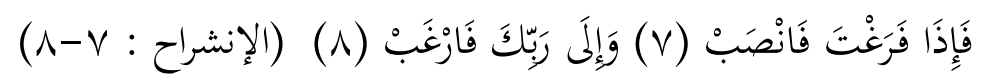

Artinya :"(7) Maka apabila kamu telah selesai (dari suatu urusan) kerjakanlah dengan sungguh-sungguh (urusan) yang lain. (8) Dan hanya kepada Tuhanmulah hendaknya

kamu berharap." (Departemen Agama RI, 2002:478)

Pada ayat tersebut sudah dijelaskan bahwasanya dalam melakukan suatu urusan hendaknya dilakukan dengan sungguh-sungguh. Tidak terkecuali menjadi seorang tenaga kependidikan, kita juga diharuskan menjadi tenaga yang profesional dan melaksanakan tugas dengan sebaikbaiknya agar dapat mencapai tujuan pendidikan yang diharapkan.

Selaras dengan hal tersebut, pemberdayaan tenaga kependidikan menjadi salah satu hal penting dan utama dalam menunjang proses pembelajaran di sekolah, untuk itu perlu dilakukan peningkatan dalam pendayagunaan dan pengelolaannya agar tujuan sekolah dapat tercapai 
secara maksimal. Pemberdayaan juga merupakan salah satu aspek manajemen dalam mengoptimalkan sumber daya organisasi, sehingga mampu memberikan optimalisasi pada sistem dan kinerjanya. Dalam dunia pendidikan proses pemberdayaan juga merupakan cara yang sangat praktis dan produktif untuk mendapatkan hasil yang terbaik dari kepala sekolah (manajer), para guru dan tenaga kependidikan lainnya. Proses yang ditempuh untuk mendapatkan hasil yang produktif tersebut adalah dengan membagi tanggung jawab secara proposional kepada seluruh tenaga kependidikan di sekolah.

Allah SWT berfirmandalam Al-Qur'an Surah Ar-Ra'dayat11 :

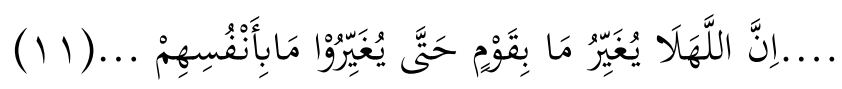

Artinya: “.... Sesungguhnya Allah tidak akan mengubah

keadaan suatu kaum sebelum mereka mengubah keadaan

diri mereka sendiri ...". (Departemen Agama RI, 2002:199)

Pada ayat di atas terdapat kata "yugayyiru" yang memiliki arti mengubah. Hal tersebut dapat diartikan bahwa apabila seseorang ingin menjadi lebih baik atau ingin mencapai suatu yang kita harapkan kita harus berusaha dari diri sendiri terlebih dahulu. Begitu juga suatu instansi pendidikan apa bilaingin mencapai tujuan secara maksimal, harus merubah dan mengelola secara maksimal sumber daya yang ada agar dapat mencapai tujuan pendidikan secara efektif dan efisien. Tenaga kependidikan merupakan salah satu sumber daya dalam dunia pendidikan yang harus selalu diperhatikan dan dikelola dengan baik.

UU nomor 20 pasal 13 tahun 2003 tentang Sistem Pendidikan Nasional dan PP 19 pasal 1 ayat 7 tahun 2005 tentang Standar Nasional Pendidikan dinyatakan bahwa pendidik dan tenaga kependidikan adalah kriteria pendidikan pra-jabatan dan kelayakan fisik maupun mental serta pendidikan dalam jabatan. Pendidikan adalah tenaga kependidikan yang berkualifikasi sebagai guru, dosen, konselor, pamong belajar, fasilitator 
dan sebutan lain yang sesuai dengan kekhususannya serta berpartisipasi dalam menyelenggarakan pendidikan. Sedangkan, tenaga kependidikan ialah anggota masyarakat yang mengabdikan diri dan diangkat untuk menunjang penyelenggaraan pendidikan (UU SISDIKNAS No 20 Tahun 2003, Bab I pasal 1, ayat 5 dan ayat 6). Berdasarkan ketentuan undangundang tersebut dapat dipahami bahwa tenaga kependidikan adalah tenaga profesional yang bertugas untuk menunjang terselenggaranya kegiatan pendidikan di lembaga pendidikan. Tenaga kependidikan bertugas melaksanakan administrasi, pengelolaan, pengembangan, pengawasan dan pelayanan teknis untuk menunjang proses pendidikan pada satuan pendidikan (UU SISDIKNAS No 20 Tahun 2003, Bab XI Pasal 39, ayat 1). Tenaga kependidikan meliputi pengelola satuan pendidikan, pamong belajar, pengawas, peneliti, pengembang, pustakawan, laboran dan teknisi sumber belajar (UU SISDIKNAS No 20 Tahun 2003, Penjelasan Pasal 39, ayat 1$)$.

Tenaga kependidikan lainnya yakni orang yang berpartisipasi alam penyelenggaraan pendidikan disatuan pendidikan, walaupun secara tidak langsung terlibat dalam proses pendidikan, diantaranya :

1. Wakil wakil/kepala urusan umumnya pendidik yang mempunyai tugas tambahan dalam bidang yang khusus, untuk membantu kepala satuan pendidikan dalam penyelenggaraan pendidikan pada institus tersebut. Contoh kepala urusan kurikulum.

2. Tata usaha adalah tenaga kependidikan yang bertugas dalam bidang adminisrasi intsitusi tersebut. Bidang administrasi yang dikelolanya adalah administrasi surat menyurat dan pengarsipan, administrasi kepegawaian, administrasi peserta didik, administrai keuangan, administrasi inventaris dan lain lain.

3. Laboran adalah petugas khusus yang bertanggung jawab terhadap alatalat dan bahan di laboratorium.

4. Pustakawan adalah petugas yang bertanggung jawab atas ketertiban peminjaman dan pengembalian buku.

Empowering Tenaga Kependidikan di MA Unggulan Mukhtar Syafa'at Blokagung 
5. Pelatih ekstra kulikuler yaitu petugas yang bertanggungjawab atas program ekstrakuliler yang ada di sekolah.

Berdasarkan profil yang didapat saat observasi awal, MA Unggulan Mukhtar Syafa'at adalah salah satu sekolah yang terletak di ujung timur pulau jawa. Tepatnya di Dusun Blokagung Desa Karangdoro Kec. Tegalsari Kab. Banyuwangi. Dan berada di bawah naungan Yayasan Mukhtar Syafa'at. Dalam proses manajerialnya semuanya sangat berhubungan erat dengan Yayasan Mukhtar Syafa'at. Termasuk dalam proses rekrutmen tenaga pendidik dan tenaga kependidikannya. MA Unggulan Mukhtar Syafa'at tidakakan dapat merekrut pegawai baru kecuali mendapatkan persetujuan dari pihak Yayasan Mukhtar Syafa'at. Saat ini, MA Unggulan Mukhtar Syafa'at memiliki 8 orang tenaga kependidikan, yang mana seluruh tenaga kependidikan tersebut merangkap sebagai seorang tenagapendidik.

Hasil observasi awal di MA Unggulan Mukhtar Syafa'at permasalahan yang muncul adalah masih kurangnya tenaga kependidikan yang tersedia. Terlebih masih terdapat pula beberapa pendidik yang kurang menguasai 4 kompetensi yang harus dimiliki pendidik sehingga hal ini menyebabkan adanya proses belajar mengajar yang kurang efektif dalam melaksanakan tugasnya dan masih kurangnya tenaga kependidikan di sekolah tersebut. Seperti yang dipaparkan oleh Bapak Masrukin :

“Tenaga kependidikan di MA Unggulan Mukhtar Syafa'at saat ini berjumlah 8 orang. Dan kesemuanya itu merangkap tugas sebagai seorang tenaga pendidik. Dengan jumlah sedemikian itu sebenarnya masih kurang. Karena ada beberapa tugas yang belumterisi. Di sisi lain, dari pihak yayasan belum memperbolehkan adanya rekrutmen pegawai baru. Jadi, mau tidak mau tenaga kependidikan yang ada itulah yang merangkap tugas”. (Sumber : Wawancara, 22 Juli 2020) 
Berdasarkan keterangan yang dipaparkan oleh Bapak Masrukin tersebut, sudah jelas bahwa masih kurangnya tenaga kependidikan yang tersedia di MA Unggulan Mukhtar Syafa'at. Dengan jumlah sedemikian itu tentu belum mencukupi untuk semua tugas yang harus dipenuhi bagi sebuah instansi pendidikan. Selaras dengan hal tersebut, WaKa. Kurikulum memaparkan keterangan mengenai pembagian tugas tenaga pendidik dan kependidikan yang ada di MA Unggulan Mukhtar Syafa'at beliau mengungkakan bahwa :

"Pembagian tugas tenaga pendidik dan kependidikan yang ada di MA Unggulan Mukhtar Syafa'at sudah dilakukan sesuai dengan bidang keahliannya masing-masing. Namun, karena keterbatasan tenaga pendidik dan tenaga kependidikan akhirnya masih ada tenaga pendidik yang mendapatkan mata pelajaran yang harus diampu tidak sesuai dengan bidang akademiknya dan tenaga kependidikan yang mendapatkan tugas tidak sesuai dengan skill yang dimiliki. Begitu juga ada beberapa job pekerjaan yang belum dipenuhi karena kurangnya pegawai. (Sumber:

Wawancara, Juli 2020)

Berdasarkan ungkapan Bapak WaKa. Kurikulum dapat dipahami bahwa untuk pembagian tugas tenag pendidik dan kependidikan yang ada di MA Unggulan Mukhtar Syafa'at sudah sesuai dengan bidang keahliannya masing-masing. Hanya saja, karena adanya keterbatasan pegawai akhirnya masih terdapat tenaga pendidik yang mengajar belum sesuai dengan bidang keahliannya dan tenaga kependidikan yang mendapatkan tugas tidak sesuai dengan kemampuannya terlebih masih terdapat tugas yang belum diisi karena belum adany tenaga kependidikan yang memadai.

Berdasarkan permasalahan di atas, kurang efektifnya pembagian tugas bagi tenaga kependidikan di MA Unggulan Mukhtar Syafa'at menjadi salah satu aspek yang mempengaruhi proses pemberdayaan yang

Empowering Tenaga Kependidikan di MA Unggulan Mukhtar Syafa'at Blokagung Banyuwangi

Siti Aimah, Umi Nur Syarifah 
seharusnya dilakukan secara maksimal demi mencapai tujuan pendidikan secara efektif dan efisien. Di mana proses pemberdayaan tenaga kependidikan yang baik harus di mulai dari rekrutmen sampai evaluasi tenaga kependidikan sehingga mampu mencapai tujuan dari pendidikan itu sendiri. Jika dari pemberdayaan tenaga kependidikan saja tidak dilakukan dengan baik bagaimana tujuan pendidikan akan bisa sampai pada hasil yang diinginkan.

\section{Rumusan Masalah}

a. Bagaimana rekrutmen tenaga kependidikan di MA Unggulan Mukhtar Syafa'at Blokagung Tegalsari Banyuwangi Tahun Pembelajaran 2019/2020?

b. Bagaimana placement/penempatan tenaga kependidikan di MA Unggulan Mukhtar Syafa'at Blokagung Tegalsari Banyuwangi Tahun Pembelajaran 2019/2020?

c. Bagaimana pemberdayaan tenaga kependidikan di MA Unggulan Mukhtar Syafa'at Tahun Pembelajaran 2019/2020?

d. Apa saja faktor pendukung dan penghambat proses pemberdayaan tenaga kependidikan di MA Unggulan Mukhtar Syafa'at Blokagung Tegalsari Banyuwangi Tahun pembelajaran 2019/2020?

\section{Tujuan Penelitian}

a. Mengetahui rekrutmen tenaga kependidikan di MA Unggulan Mukhtar Syafa'at Blokagung Tegalsari Banyuwangi Tahun Pembelajaran 2019/2020.

b. Mengetahui placement/penempatan tenaga kependidikan di MA Unggulan Mukhtar Syafa'at Blokagung Tegalsari Banyuwangi Tahun Pembelajaran 2019/2020.

c. Mengetahui pemberdayaan tenaga kependidikan di MA Unggulan Mukhtar Syafa'atTahun Pembelajaran 2019/2020.

d. Mengetahui faktor pendukung dan penghambat proses pemberdayaan tenaga kependidikan di MA Unggulan Mukhtar Syafa'at Blokagung Tegalsari Banyuwangi Tahun Pembelajaran 2019/2020.

Empowering Tenaga Kependidikan di MA Unggulan Mukhtar Syafa'at Blokagung 


\section{B. LandasanTeori}

\section{Rekrutmen Tenaga Kependidikan}

Rekrutmen yang efektif dipengaruhi oleh bagaimana organisasi dapat melaksanakan sejumlah kegiatan ini di dalam proses tersebut. Menurut Stoner yang dikutip oleh Syamsudin (2010 : 40), kegiatan yang dilaksanakan dalam proses rekrutmen adalah sebagai berikut :

a. Menentukan dan membuat kategori kebutuhan Sumber Daya Manusia jangka pendek dan jangka panjang.

b. Selalu memperhatikan perubahan kondisi di dalam pasar tenaga kerja.

c. Mengembangkan media (promosi) rekrutmen yang paling sesuai untuk para pelamar.

d. Menyimpan data tentang jumlah dan kualitas pelamar pekerja dari setiap sumber.

e. Menindaklanjuti dari setiap permohonan pelamar kerja untuk kemudian melakukan evaluasi efektifitas dengan upaya rekrutmen yang telah dilakukan.

\section{Placement Tenaga Kependidikan}

Placement atau penempatan yaitu proses penanganan pegawai baru yang sudah melaksanakan pendaftaran untuk diberitahu bahwa di bagian mana kita ditempatkan. Penugasan dilakukan sesuai dengan bidang keahlian dan kebutuhan lembaga.Menurut Mathis dan Jackson (2006 : 262) menyatakan bahwa penempatan adalah menempatkan posisi seseorang ke posisi pekerjaan yang tepat, seberapa baik seorang pegawai cocok dengan pekerjaannya akan mempengaruhi jumlah dan kualitas pekerjaan.

\section{Empowering Tenaga Kependidikan}

Empowering atau pemberdayaan tenaga kependidikan merupakan suatu proses di mana tenaga kependidikan menjadi mampu dalam berbagai hal pada bidang keahliannya yang pada akhirnya akan memberikan dampak positif terhadap kehidupan tenaga kependidikan yang 
bersangkutan. Wahyudi (2012 : 25-26) Pemberdayaan adalah terjemahan dari kata empowerment, yang berasal dari kata "empower" yang mengandung pengertian, (1) to give power to (memberi kekuasaan, kekuatan pada pihak lain) (2) to give ability to (usaha untuk memberikan kemampuan). Dalam Bahasa Indonesia, pemberdayaan berasal dari kata dasar "daya", yang berarti kekuatan atau tenaga, ada juga yang mengartikan sebagai potensi yang dapat menggerakan sesuatu.

4. Faktor Pendukung dan Penghambat Proses Empowering Tenaga Kependidikan

Agar pemberdayaan sumber daya manusia di sekolah dapat dilaksanakan secara optimal, menurut Slamet P.H dalam Barlian (2013: 13) dibutuhkan kreativitas kepala sekolah untuk melakukan upaya-upaya pemberdayaan terhadap stafnya, baik ademik maupun administrasi dengan cara : (1) Merancang suatu jabatan yang memberikan rasa memiliki dan tanggung jawab; (2) Mengupayakan terbentuknya kerja sama kelompok; (3) Mengupayakan peningkatan kemampuan dan kesanggupan kerja seseorang; (4) Memberikan pendelegasian dan melakukan pengawasan yang jelas; (5) Menyusun secara bersama visi, misi, tujuan, dan strategi yang jelas yang dapat diterima oleh warganya; (6) Mengomunikasikan secara efekttif tentang rencana, implementasi, dan hasil kerja; (7) Mengupayakan sistem yang memberdayakan semua orang terhadap komunikasi. Kompensasi, evaluasi, disiplin, kebijakan personal, seleksi, promosi, informasi pelatihan dan pengembangan serta pengembangan karir.

\section{PenelitianTerdahulu}

1. Syafri Alisman (2012), judul penelitian yaitu: "Usaha Kepala Sekolah Memberdayakan Sumber Daya Eksternal dalam Meningkatkan Mutu Pendidikan di Madrasah Tsanawiyah Desa Sawah Kecamatan Kampar Utara Kabupaten Kampar". Penelitian ini menggunakan metode kualitatif dengan jenis deskriptif. Kesimpulan penelitian ini bahwa usaha kepala sekolah memberdayakan sumber daya eksternal dalam

Empowering Tenaga Kependidikan di MA Unggulan Mukhtar Syafa'at Blokagung Banyuwangi

Siti Aimah, Umi Nur Syarifah 
meningkatkan mutu pendidikan di Madrasah Tsanawiyah Desa Sawah Kecamatan Kampar Utara secara keseluruhan termasuk ke dalam kategori sangat baik.

2. Ulfah Novitasari (2018), Pemberdayaan Guru di SMP Muhammadiyah 4 Sambi Kabupaten Boyolali. Penelitian ini menggunakan metode kualitatif dengan jenis deskriptif. Analisis dalam penelitian ini menggunakan interaktif tiga model. Hasil penelitian menunjukkan bahwa pemberdayaan guru di SMP Muhammadiyah 4 Sambi Boyolali telah terlaksana.

3. Desi Eri Kusumaningrum (2010), Pemberdayaan Tenaga Administrasi Sekolah Menengah Pertama Berbasis Pesantren. Penelitian ini menggunakan metode kuantitatif. Hasil penelitian ini dapat disimpulkan bahwa tingkat pemberdayaan TAS SMP berbasis pesantren di Jawa Timur dengan 90 termasuk dalam kategori cukup baik.

Tabel 1.1

Persamaan dan Perbedaan dalam Penelitian

\begin{tabular}{|c|c|c|c|}
\hline No & Judul & Persamaan & Perbedaan \\
\hline 1. & $\begin{array}{l}\text { Usaha Kepala } \\
\text { Sekolah } \\
\text { Memberdayakan } \\
\text { Sumberdaya } \\
\text { Eksternal dalam } \\
\text { Meningkatkan } \\
\text { Mutu Pendidikan di } \\
\text { Madrasah } \\
\text { Tsanawiyah Desa } \\
\text { Sawah Kecamatan } \\
\text { Kampar Utara } \\
\text { Kabupaten } \\
\text { Kampar. }\end{array}$ & $\begin{array}{l}\text { a. Tema yang sama } \\
\text { yakni pemberdayaan } \\
\text { SDM } \\
\text { b. Metode yang sama } \\
\text { yakni kualitatif }\end{array}$ & $\begin{array}{l}\text { a. Objek yang } \\
\text { berbeda } \\
\text { b. Tahun penelitian } \\
\text { yang berbeda }\end{array}$ \\
\hline 2. & $\begin{array}{l}\text { Pemberdayaan } \\
\text { Guru di SMP } \\
\text { Muhammadiyah } 4 \\
\text { Sambi Kabupaten } \\
\text { Boyolali. }\end{array}$ & $\begin{array}{ll}\text { a. } & \text { Tema yang } \\
& \text { samayaknipemberday } \\
& \text { aan SDM } \\
\text { b. } & \text { Metode yang } \\
& \text { samayakniKualitatif }\end{array}$ & $\begin{array}{l}\text { a. Objek yang } \\
\text { berbeda } \\
\text { b. Tahun penelitian } \\
\text { yang berbeda }\end{array}$ \\
\hline 3. & Pemberdayaan & a. Tema yang & a. Objek \\
\hline
\end{tabular}

Empowering Tenaga Kependidikan di MA Unggulan Mukhtar Syafa'at Blokagung Banyuwangi

Siti Aimah, Umi Nur Syarifah 
JMPID (Jurnal Manajemen Pendidikan Islam Darussalam)

Jurnal Manajemen Pendidikan Islam

Volume: 2, Nomor: 2, September 2020

ISSN : 2722-7146 (online)

\begin{tabular}{|l|l|l|}
\hline Tenaga & samayaknipemberday & berbeda \\
Administrasi & aan SDM & b. Tahunpenelitian \\
Sekolah Menengah & & yang berbeda \\
Pertama Berbasis & & $\begin{array}{l}\text { Metode yang } \\
\text { digunakankuantit } \\
\text { Pesantren. }\end{array}$ \\
\hline
\end{tabular}

(Sumber : Data OlahanPeneliti, Mei 2020)

Dari Tabel 1.1 tersebut dapat disimpulkan bahwa pembaharuan dalam penelitian ini dengan penelitian terdahulu yaitu meskipun tema yang diteliti sama akan tetapi objek dan metode penelitian berbeda sehingga akan menghasilkan hasil yang berbeda pula.

\section{Metode Penelitian}

\section{Pendekatan dan Jenis Penelitian}

Penelitian in imenggunakan pendekatan fenomenologi dengan jenis penelitian deskriptif kualitatif yakni prosedur penelitian yang menggunakan data deskriptif berupa kata-kata tertulis atau lisan dari orang-orang dan prilaku yang diamati. Pendekatan fenomenologi berusaha melihat dan memahami subyek dan obyek penelitian (seseorang, masyarakat, maupun lembaga) berdasarkan fakta yang tampak secara apa adanya. Pada penelitian ini penulis berfokus pada proses empowering tenaga kependidikan di MA Unggulan Mukhtar Syafa'at.

\section{Lokasi Penelitian}

Lokasi penelitian ini ialah MA Unggulan Mukhtar Syafa'at Blokagung Tegalsari Banyuwangi.

\section{Sumber Data}

Sumber data yang digunakan dalam penelitian ini ada dua yaitu :sumber data primer dan sekunder.. Sumber data primer adalah sumber data yang diperoleh melalui proses wawancara langsung dengan kepala madrasah sebagai informan kunci terkait gambaran umum tenaga kependidikan yang ada dan observasi langsung di lembaga untuk mendapatkan data berupa kondisi nyata masalahp enelitian. Sedangkan

Empowering Tenaga Kependidikan di MA Unggulan Mukhtar Syafa'at Blokagung 
sumber data sekunder didapat dari bagian tata usaha dan WaKa. Kurikulum sebagai informan pendukung untuk mendapatkan data terkait administrasi dan data pendukung penelitian berupa proses wawancara terkait pembagian tugas tenaga kependidikan, profil madrasah dan perangkat pendidikan.

\section{Teknik Pengumpulan Data}

Teknik pengumpulan data pada penelitian ini menggunakan wawancara, observasi dan dokumentasi.sesuai dengan pendapat Sugiono (2015:309) tentang teknik pengumpulan data penelitian kualitatif dilakukan pada natural setting (kondisi alami), sumber data primer dan teknik pengumpulan data lebih banyak pada observasi berperan serta, wawancara mendalam dan dokumentasi.

\section{Teknik Analisis Data}

Analisis data dalam penelitian ini menggunakan analis interaktif tiga model yakni kondensasi data, penyajian data dan kesimpulan.

\section{Hasil Penelitian}

1. Data tentang rekrutmen tenaga kependidikan di MA Unggulan Mukhtar Syafa'at Blokagung Tegalsari Banyuwangi Blokagung Tegalsari Banyuwangi

Dalam penelitian ini telah menemukan proses perekrutan tenaga kependidikan di MA Unggulan Mukhtar Syafa'at Blokagung Tegalsari Banyuwangi, sebagai berikut :

a. Kepala Madrasah menganalisis kebutuhan tenaga kependidikan berdasar kekosongan bidangk erja

Sebelum mengadakan rekrutmen pegawai baru, kepala madrasah terlebih dulu menganalisis pekerjaan atau jabatan mana yang membutuhkan rekrutmen tenaga kependidikan. Hal tersebut dilakukan dengan bentuk monitoring dan evaluasi yang dilaksanakan berupa observasi langsung oleh kepala madrasah minimal setiap satu bulan sekali dan dilaksanakan pula rapat bersama seluruh tenaga 
kependidikan MA Unggulan Mukhtar Syafa'at Blokagung Tegalsari Banyuwangi minimal setiap satu semester sekali. Dari sinilah kepala madrasah dapat mengambil keputusan tentang perlunya diadakan proses rekrutmen tenaga kependidikan atau tidak.

b. Mengadakan promosi rekrutmen tenaga kependidikan sesuai kebutuhan

Tahap selanjutnya setelah kepala madrasah menganalisis mengenai kebutuhan tenaga kependidikan yakni diadakannya promosi terkait rekrutmen tenaga ependidikan baru. Promosi rekrutmen tenaga kependidikan baru di MA Unggulan Mukhtar Syafa'at Blokagung Tegalsari Banyuwangi dilakukan hanya dengan menggunakan pesan berantai saja. Tidak pernah menggunakan brosur.

c. Mengadakan seleksi dalam perekrutan tenaga kependidikan

Proses seleksi sangatlah dibutuhkan dalam rekrutmen tenaga kependidikan. Karena dari hasil seleksi inilah dapat diketahui layak atau tidaknya seseorang diangkat sebagai tenaga kependidikan yang baru. Proses seleksi yang dilakukan di MA Unggulan Mukhtar Syafa'at Blokagung Tegalsari Banyuwangi meliputi kelengkapan berkas-berkas yang wajib dilampirkan dan proses wawancara yang dilakukan oleh pihak dari yayasan didampingi dengan kepala MA Unggulan Mukhtar Syafa'at Blokagung Tegalsari Banyuwangi.

d. Meminta persetujuan pengurus yayasan dalam perekrutan tenaga kependidikan

Proses rekrutmen selanjutnya sebelum ditetapkannya pegawai baru, terlebih dulu pihak MA Unggulan Mukhtar Syafa'at Blokagung Tegalsari Banyuwangi menyetorkan nama calon pegawai kepadap ihak Yayasan Mukhtar Syafa'at. Hal ini terjadi karena ketika belum ada izin dari pihak yayasan maka lembaga pendidikan MA Unggulan Mukhtar Syafa'at Blokagung Tegalsari Banyuwangi tidak akan dapat merekrut pegawai baru.

e. Pengajuan SK tenaga kependidikan baru kepada pengurus yayasan

Empowering Tenaga Kependidikan di MA Unggulan Mukhtar Syafa'at Blokagung 
Kegiatan rekrutmen tenaga kependidikan baru tersebut setiap tenaga kependidikan yang telah memenuhi berbagai persyaratan tersebut dan telah lulus seleksi selanjutnya akan diberi SK tenaga kependidikan oleh pihak yayasan sebagai bukti telah diterimanya sebagai tenaga kependidikan baru.

f. Penerbitan SK Tenaga kependidikan

Proses selanjutnya yakni penerbitan SK tenaga kependidikan oleh pihak Yayasan Mukhtar Syafa'at Blokagung Karangdoro Banyuwangi. SK tenaga kependidikan diterbitkan setelah calon tenaga kependidikan tersebut sudah melaksanakan serangkaian ketentuan dari proses rekrutmen tenaga kependidikan.

g. Pemberian SK kepada tenaga kependidikan yang lulus seleksi dan mendapat persetujuan pengurus yayasan

Proses pemberian SK kepada tenaga kependidikan dilakukan secara langsung dengan memanggil tenaga kependidikan baru di MA Unggulan Mukhtar Syafa'at Blokagung Tegalsari Banyuwangi. Hal tersebut dilakukan agar seorang tenaga kependidikan baru dapat langsung mengikuti proses selanjutnya.

h. Pengenalanaturan dan budaya organisasi kepada tenaga kependidikan yang baru

Bersamaan dengan diberikannya SK kepada tenaga kependidikan baru, saat itu pula kepala madrasah melakukan pengenalan terkait aturan dan budaya organisasi yang ada. Dari awal, proses rekrutmen tenaga kependidikan yang ada di MA Unggulan Mukhtar Syafa'at Blokagung Tegalsari Banyuwangi lebih mengedepankan alumni. Karena seorang alumni pasti sudah mengerti bagaimana aturan dan budaya organisasi.

i. Penandatangan persetujuan tenaga kependidikan yang baru atas aturan yayasan

Tahap terakhir dari rangkaian proses rekrutmen yang ada di MA Unggulan Mukhtar Syafa'at Blokagung Tegalsari Banyuwangi

Empowering Tenaga Kependidikan di MA Unggulan Mukhtar Syafa'at Blokagung Banyuwangi 
yakni penandatangan surat persetujuan terkait aturan yayasan oleh tenaga kependidikan baru. Setelah penandatanganan surat persetujuan tersebut, secara langsung tenaga kependidikan tersebut bergabung dengan keluarga besar Yayasan Mukhtar Syafa'at Blokagung Tegalsari Banyuwangi.

2. Data tentang placement/penempatan tenaga kependidikan di MA

\section{Unggulan Mukhtar Syafa'at Blokagung Tegalsari Banyuwangi}

Berikut merupakan data tentang penempatan tenaga kependidikan yang ada di MA Unggulan Mukhtar Syafa'at Blokagung TegalsariB anyuwangi :

a. Penempatan tenaga kependidikan sesuai keahlian dan skill yang dimiliki

Penempatan tenaga kependidikan memang seharusnya sesuai dengan bidang keahlian dan skill yang dimiliki. Sudah 90\% penempatan tenaga kependidikan yang ada di MA Unggulan Mukhtar Syafa'at Blokagung Tegalsari Banyuwangi sesuai dengan bidang keahlian dan skill yang yangdimiliki.

b. Pembinaan tenaga kependidikan yang baru oleh pengurus yayasan

Berdasarkan paparan data yang telah dipaparkan, terlihat masih ada tenaga kependidikan yang mendapatkan tugas tidak sesuai dengan bidang keahlian dan skill yang dimiliki. Oleh sebab itu, tindakan yang dilakukan oleh pihak pengelola MA Unggulan Mukhtar Syafa'at Blokagung Tegalsari Banyuwangi yakni diadakannya proses pembinaan bagi setiap tenaga kependidikan dengan tujuan dapat meningkatkan hasil kinerja tenaga kependidikan yang diinginkan. Baik pembinaan yang bersifat internal yang dilakukan oleh pihak yayasan maupun pembinaan yang bersifat eksternal yang dilakukan oleh pihak eksternal sekolah seperti Dinas Pendidikan Banyuwangi, Cabang Dinas Pendidikan Kabupaten Banyuwangi dan Kementerian Agama kabupaten Banyuwangi dan lain sebagainya.

Empowering Tenaga Kependidikan di MA Unggulan Mukhtar Syafa'at Blokagung Banyuwangi 


\section{Data tentang pemberdayaan tenaga kependidikan di MA Unggulan} Mukhtar Syafa'at Blokagung Tegalsari Banyuwangi

Upaya-upaya pemberdayaan tersebut meliputi :

a. Evaluasi kinerja tenaga kependidikan melalui monitoring dan rapat

Sebagai langkah pertama dalam upaya pemberdayaan tenaga kependidikan adalah evaluasi kinerja yang dilakukan MA Unggulan Mukhtar Syafa'at Blokagung Tegalsari Banyuwangi Blokagung yaitu monitoring dan evaluasi berkala yang dilaksanakan berupa observasi langsung oleh kepala madrasah minimal setiap satu bulan sekali dan dilaksanakan pula rapat bersama seluruh tenaga kependidikan MA Unggulan Mukhtar Syafa'at Blokagung Tegalsari Banyuwangi Blokagung minimal setiap satu semester sekali.

b. Peningkatan SDM tenaga kependidikan dengan pelatihan sesuai bidang masing-masing

Pasca monitoring dan evaluasi agar menghasilkan tenaga kependidikan sebagai tindaklanjutnya yakni pengelola MA Unggulan Mukhtar Syafa'at Blokagung Tegalsari Banyuwangi Blokagung beruapaya meningkatkan kualitas SDM tenaga kependidikannya dengan mengikut sertakan pada berbagai pelatihan sesuai dengan bidang yang diampu oleh masing-masing tenaga kependidikan.

c. Pemberian penghargaan (reward) terhadap kinerja tenaga kependidikan dengan kenaikan jabatan dan tunjangan

Penghargaan (reward) yang diberikan pengelola MA Unggulan Mukhtar Syafa'at Blokagung Tegalsari Banyuwangi terhadap kinerja tenaga kependidikan setelah dilakukannya evaluasi kinerja tenaga kependidikan tidak menggunakan nominal tetapi dengan kenaikan jabatan lebih cepat atau pemberian penghargaan berupa sertifikat dan pemberian tugas atau job description sesuai dengan prestasi yang diraih dengan harapan setiap tenaga kependidikan yang mendapatkan penghargaan dapat mengembangkan keahliannya. Dan ketika seorang 
tenaga kependidikan naik jabatan maka secara otomatis tunjangan yang akan diterima juga akan meningkat.

d. Pemberian suratp eringatan dan sanksi pada tenaga kependidikan yang kinerjanya kurang baik

Disamping reward yang diberikan kepada tenaga kependidikan yang hasil kinerjanya baik, ada pula sanksi yang akan diberikan kepada tenaga kependidikan yang kinerjanya kurang baik atau menurun. Sanksi yang diberikan berupa surat peringatan ataupun tidak akan dinaikkan jabatannya dan bahkan terjadi pemotongan tunjangan yang diterima.

4. Data tentang faktor pendukung dan penghambat proses pemberdayaan tenaga kependidikan di MA Unggulan Mukhtar Syafa'at Blokagung Tegalsari Banyuwangi

Pada proses pemberdayaan tenaga kependidikan yang dilakukan di MA Unggulan Mukhtar Syafa'at Blokagung Tegalsari Banyuwangi faktor pendukung dan penghambatnya meliputi :

a. Faktor pendukung meliputi rekrutmen tenaga kependidikan yang sistemasis

Berdasarkan paparan data yang sudah dipaparkan dapat diketahui bahwa proses rekrutmen tenaga kependidikan yang ada di MA Unggulan Mukhtar Syafa'at Blokagung Tegalsari Banyuwangi sudah dilakukan dengan metode yang baik terlihat dari semua tenaga kependidikan yang ada sudah memenuhi syarat dan melaksanakan prosedur rekrutmen pegawai yang sudah ditetapkan.

b. Faktor penghambat meliputi kurangnya ketrampilan yang dimiliki oleh tenaga kependidikan dan belum sesuainya tingkat pendidikan pegawai dengan tugas yang diampu

1) Adanya keterbatasan pegawai yang menyebabkan masih terdapat tenaga kependidikan yang merangkap tugas dan mendapatkan tugas belum sesuai dengan bidang keahliannya 
Salah satu permasalahan yang sering terjadi dalam melakukan pemberdayaan tenaga kependidikan di MA Unggulan Mukhtar Syafa'at Blokagung Tegalsari Banyuwangi yaitu masih terjadi ketidaksesuaian penempatan personal tugas dan fungsinya, misalnya pengangkatan petugas operator sekolah hanya berdasarkan pengalaman dan bakat pelamar bukan berdasarkan latar pendidikan/akademis pelamar. Ditambah masih terjadi penempatan guru yang tidak sesuai dengan bidang keahliannya, seperti penetapan guru prakarya di MA Unggulan Mukhtar Syafa'at Blokagung Tegalsari Banyuwangi masih belum sesuai dengan bidang keahliannya yang mana beliau merupakan lulusan S1 bidang ekonomi.

2) Terdapat beberapa job pekerjaan yang belumterisi

Jumlah tenaga kependidikan di MA Unggulan Mukhtar Syafa'at Blokagung Tegalsari Banyuwangi hanyaberjumlah 8 orang. Akan tetapi tenaga kependidikan tersebut ada yang merangkap tugas sebagai seorang tenaga pendidik. Dari hasil paparan data yang didapat peneliti masih terdapat job pekerjaan yang belum dipenuhi, seperti belum adanya tukang kebun, petugas kebersihan dan penjaga gerbang.

\section{E. Pembahasan}

\section{Rekrutmen Tenaga Kependidikan di MA Unggulan Mukhtar Syafa'at} Blokagung Tegalsari Banyuwangi

a. Kepala Madrasah menganalisis kebutuhan tenaga kependidikan berdasar kekosongan bidang kerja

b. Mengadakan promosi rekrutmen tenaga kependidikan sesuai kebutuhan

c. Mengadakan seleksi dalam perekrutan tenaga kependidikan

d. Meminta persetujuan pengurus yayasan dalam perekrutan tenaga kependidikan

Empowering Tenaga Kependidikan di MA Unggulan Mukhtar Syafa'at Blokagung 
e. Pengajuan SK tenaga kependidikan baru kepada pengurus yayasan

f. Penerbitan SK tenaga kependidikan

g. Pemberian SK kepada tenaga kependidikan yang lulus seleksi dan mendapat persetujuan pengurus yayasan

h. Pengenalan aturan dan budaya organisasi kepada tenaga kependidikan yang baru

i. Penandatangan persetujuan tenaga kependidikan yang baru atas aturan yayasan

2. Placement/Penempatan Tenaga Kependidikan di MA Unggulan Mukhtar Syafa'at Blokagung Tegalsari Banyuwangi

a. Penempatan tenaga kependidikan sesuai keahlian dan skill yang dimiliki

Sudah $90 \%$ penempatan tenaga kependidikan yang ada di MA Unggulan Mukhtar Syafa'at Blokagung Tegalsari Banyuwangi sesuai dengan bidang keahlian dan skill yang dimiliki.

b. Pembinaan tenaga kependidikan yang baru oleh pengurus yayasan

MA Unggulan Mukhtar Syafa'at Blokagung Tegalsari Banyuwangi mengadakan proses pembinaan bagi setiap tenaga kependidikan dengan tujuan dapat meningkatkan hasil kinerja tenaga kependidikan yang diinginkan. Baik pembinaan yang bersifat internal yang dilakukan oleh pihakyayasanmaupunpembinaan yang bersifat eksternal yang dilakukan oleh pihak eksternal sekolah seperti Dinas Pendidikan Banyuwangi, Kementrian Agama Kabupaten Banyuwangi.

3. Pemberdayaan Tenaga Kependidikan di MA Unggulan Mukhtar Syafa'at

a. Evaluasi kinerja tenaga kependidikan melalui monitoring dan rapat

b. Peningkatan SDM tenaga kependidikan dengan pelatihan sesuai bidang masing-masing

c. Pemberian penghargaan (reward) terhadap kinerja tenaga kependidikan dengan kenaikan jabatan dan tunjangan 
d. Pemberian surat peringatan dan sanksi pada tenaga kependidikan yang kinerjanya kurang baik

\section{Faktor Pendukung dan Penghambat Proses Pemberdayaan Tenaga} Kependidikan di MA Unggulan Mukhtar Syafa'at Blokagung Tegalsari Banyuwangi

a. Faktor pendukung meliputi rekrutmen tenaga kependidikan yang sistemasis

Proses rekrutmen tenaga kependidikan yang ada di MA Unggulan Mukhtar Syafa'at Blokagung Tegalsari Banyuwangi sudah dilakukan dengan metode yang baik terlihat dari semua tenaga kependidikan yang ada sudah memenuhi syarat dan melaksanakan prosedur rekrutmen pegawai yang sudah ditetapkan.

b. Faktor penghambat meliputi kurangnya ketrampilan yang dimiliki oleh tenaga kependidikan dan belum sesuainya tingkat pendidikan pegawai dengan tugas yang diampu

1) Adanya keterbatasan pegawai yang menyebabkan masih terdapat tenaga kependidikan yang merangkap tugas dan mendapatkan tugas belum sesuai dengan bidang keahliannya

2) Terdapat beberapa job pekerjaan yang belumterisi

\section{F. Kesimpulan}

1. Rekrutmen tenaga kependidikan di MA unggulan Mukhtar Syafa'at Blokagung Tegalsari Banyuwangi

Proses rekrutmen tenaga kependidikan di MA unggulan Mukhtar Syafa'at Blokagung Tegalsari Banyuwangi sudah berjalan secara sistematis. Terbukti dengan sudah adanya beberapa tahapan rekrutmen yang diterapkan. Mulai dari kegiatan monitoring dan evaluasi kinerja tenaga kependidikan yang dilaksanakan langsung oleh kepala madrasah dengan tujuan menganalisis kebutuhan dan dilanjutkan dengan mempromosikan adanya rekrutmen tenaga kependidikan melalui pesan berantai. Tahap selanjutnya berupa proses penyeleksian calon tenaga 
kependidikan melalui pengumpulan berkas seperti KTP, Ijazah pendidikan, sertifikat penghargaan dan adanya proses wawancara serta meminta persetujuan dan pengajuan SK tenaga kependidikan kepada pihak yayasan. Setelah diterbitkannya SK tenaga kependidikan oleh yayasan selanjutnya SK akan diberikan secara langsung oleh kepala madrasah kepada calon tenaga kependidikan bersamaaan dengan pengenalan aturan dan budaya yang ada, dan diakhiri dengan penandatanganan surat persetujuan oleh tenaga kependidikan baru.

2. Penempatan tenaga kependidikan di MA unggulan Mukhtar Syafa'at Blokagung Tegalsari Banyuwangi

Placement tenaga kependidikan yang ada di di MA unggulan Mukhtar Syafa'at Blokagung Tegalsari Banyuwangi sudah sesuai dengan bidang keahlian dan skill yang dimiliki yang kemudian diimbangi dengan adanya pembinaan yang dilaksanakan oleh pihak yayasan.

3. Pemberdayaan tenaga kependidikan di MA unggulan Mukhtar Syafa'at Blokagung Tegalsari Banyuwangi

Proses pemberdayaan demi meningkakan kinerja tenaga kependidikan yang ada di MA unggulan Mukhtar Syafa'at Blokagung Tegalsari Banyuwangi yang dilakukan selama ini sudah berjalan dengan baik. Seperti sudah adanya pelatihan dan pembinaan yang sesuai dengan bidang keahlian, yang kemudian dievaluasi oleh kepala madrasah minimal setiap bulan sekali baik dengan kegiatan monitoring langsung maupun dengan rapat bersama seluruh personalia. Bagi tenaga kependidikan yang hasil kinerjanya baik, maka akan mendapat penghargaan (reward) berupa kenaikan jabatan dan tunjangan. Namun, sebaliknya jika terdapat tenaga kependidikan yang kinerjanya kurang baik atau bahkan menurun maka akan mendapatkan sanksi yang berupa surat peringatan maupun pemotongan tunjangan.

4. Faktor pendukung dan penghambat proses pemberdayaan tenaga kependidikan di MA unggulan Mukhtar Syafa'at Blokagung Tegalsari Banyuwangi

Empowering Tenaga Kependidikan di MA Unggulan Mukhtar Syafa'at Blokagung 
Adanya proses rekrutmen tenaga kependidikan yang sangat sistematis yang diterapkan di MA unggulan Mukhtar Syafa'at Blokagung Tegalsari Banyuwangi menjadi faktor yang sangat mendukung terhadap berlangsungnya proses pemberdayaan tenaga kependidikan. Namun, masih ada pula beberapa hal yang menjadi faktor penghambat terhadap proses pemberdayaan tenaga kependidikan tersebut, yakni masih adanya keterbatasan pegawai yang menyebabkan masih terdapat tenaga kependidikan yang merangkap tugas dan mendapatkan tugas belum sesuai dengan bidang keahliannya dan terlebih masih terdapat beberapa job pekerjaan yang belum terisi.

\section{G. Daftar Pustaka}

Al-Rasyidin. 2008. Falsafah Pendidikan Islami. Malang: Cita Pustaka Media Perintis

Afriansyah, H. 2019. Administrasi Pendidik dan Tenaga Kependidikan. Padang: Osf. Io.

Afrizal. 2014. MetodePenelitianKualitatif. Jakarta :Rajawali Pers

Danim, Sudarwan \& Khairil. 2015. Profesi Kependidikan. Bandung: PT. Bumi Aksara

Departemen Agama RI. 2002. Al-Qur'an Al-Karim Dan Terjemahnya. Semarang: PT. KaryaToha Putra

Handoko, T. Hani. 1989. Manajemen Personalia \& Sumber Daya Manusia. Yogyakarta: Bpfe Yogyakarta

Manulang, Marohot. 2008. Manajemen Personalia. Yogyakarta: Gajah Mada University Press

Moleong, Lexi J. 2014. Metodologi Penelitian Kualitatif. Bandung: PT. Remaja Rosdakarya

Mulyasa, E. 2007. Kurikulum Berbasis Kompetensi. Bandung: Remaja Rosdakarya

Mulyasa. 2012. Manajemen \& Kepemimpinan Kepala Sekolah. Jakarta: Bumi Aksara

Empowering Tenaga Kependidikan di MA Unggulan Mukhtar Syafa'at Blokagung Banyuwangi

Siti Aimah, Umi Nur Syarifah 
Qomar, Mujamil. 2007. Manajemen Pendidikan Islam Strategi Baru Pengelolaan Lembaga Pendidikan Islam. Malang: Erlangga

Riduwan. 2010. Manajemen Pendidikan. Bandung: Alfabeta

Rivai, Veithzal. 2009. Islamic Human Capital Ed 1. Jakarta: Rajawali Press

Sagala, Syaiful. 2013. KemampuanProfesional Guru Dan Tenaga Kependidikan. Bandung: Alfabeta

Sugiono. 2015. MetodePenelitian. Bandung : PT. Pustaka

Sukirno, Sadono. 2011. PengantarBisnis. Jakarta: Kencana

Syamsudin, Sadili. 2010. Manajemen Sumber Daya Manusia. Bandung: CV. Pustaka Setia

Ulfatin, Nurul dan Triwiyanto, Teguh. 2016. Manajemen Sumber Daya Manusia Bidang Pendidikan. Jakarta: Rajawali Pers

Undang-Undang N0. 14 Tahun 1969 Tentang Tenaga Kerja.

Undang-Undang RI No. 20 Tahun 2003. 2010. Sisdiknas dan Peraturan Pemerintah Tahun 2010 tentang Penyelenggaraan Pendidikan Serta Wajib Belajar. Bandung: Citra Umbara

Wahyudi, Imam. 2012. Pengembangan Pendidikan (StrategiInovatif dan Kreatif dalam Mengelola Pendidikan Secara Komprehensif), Jakarta: PT. Prestasi Pustakarya

Yusraini. 2012. Implementasi Manajemen Sumber DayaManusia : Tenaga Pendidik dan Kependidikan Untuk Meningkatkan Mutu Layanan Pendidikan. Bandung: Cipta Pustaka 